Moroccan J. of Pure and Appl. Anal. (MJPAA)

Volume 5(2), 2019, Pages 197-221

ISSN: Online 2351-8227- Print 2605-6364

DOI 10.2478/mjpaa-2019-0015

\title{
Common coupled fixed point theorems for two pairs of weakly compatible mappings in Menger metric spaces
}

\author{
Abdelkrim Abdelhalim ${ }^{1}$, Abdelkrim Aliouche ${ }^{2}$, Leila Ben Aoua ${ }^{3}$, Oussaeif Taki-Eddine ${ }^{4}$
}

Aвstract. In this paper, we prove some common coupled fixed point theorems for contractive mappings in Menger metric spaces under geometrically convergent t-norms. Also, we prove common fixed point theorems for pairs of weakly compatible mappings, which generalize the results of Jian-Zhong Xiao and al (2011). The main results is supported by a suitable examples.

Mathematics Subject Classification (2010). 47H10, 54H25.

Key words and phrases. First keyword, Second Menger metric space, g-convergent t-norm, t-norm of H-type, weak compatibility, coupled common fixed point.

\section{Introduction}

Many common coupled fixed point theorems for contractions in probabilistic metric spaces under either a t-norm of Hadzic-type or the t-norm $\triangle_{p}=$ prod can be found in the recent literatur, see, e.g, $[3,4,5,17,20,21,22]$. The aim of this paper is to obtain similar results in a larger class of Menger metric spaces,namely in Menger metric spaces endowed with geometrically convergent t-norms.

We assume that the reader is familiar with the basic concepts and terminology of the theory of Menger metric spaces. We only recall that a t-norm $\triangle$ is said to be of Hadzic-type (denoted

Received 5 July 2019 - Accepted: 10 December 2019.

(c) The Author(s) 2017. This article is published with open access by Sidi Mohamed Ben Abdallah University.

1,2,3,4 Department of Mathematics and Informatics, Larbi Ben M'hidi University, Oum El Bouaghi, 04000, Algeria.

e-mail: ${ }^{1}$ mathhalim@yahoo.fr

e-mail: ${ }^{2}$ alioumath@yahoo.fr

e-mail: ${ }^{3}$ benaoualeila@gmail.com

e-mail: ${ }^{4}$ taki_maths@live.fr. 
$\triangle \in H)$ if the family $\left\{\triangle^{n}(t)\right\}_{n=1}^{\infty}$ defind by

$$
\triangle^{1}(t)=t, \triangle^{n+1}(t)=\triangle\left(t, \triangle^{n}(t)\right) \quad n=1,2, \ldots \quad t \in[0,1]
$$

is equi-continuous at $t=1$, and that a t-norm $\triangle$ is called geometrically convergent (or gconvergent) [7] if for all $q \in(0,1)$,

$$
\lim _{n \rightarrow \infty} \triangle_{I=n}^{\infty}\left(1-q^{i}\right)=1 .
$$

It is worth noting (see e.g, [7]) that if for a t-norm there exists $q_{0} \in(0,1)$ such that

$$
\lim _{n \rightarrow \infty} \triangle_{i=n}^{\infty}\left(1-q_{0}^{i}\right)=1
$$

then

$$
\lim _{n \rightarrow \infty} \triangle_{i=1}^{\infty}\left(1-q^{i}\right)=1
$$

The well known t-norms $\triangle_{M}=\min , \triangle_{p}=\operatorname{prod}$ and $\triangle_{L}$ (Lukasiewiez t-norm) are g-convergent.

Also, every member of Domby family $\left(\triangle_{\lambda}^{D}\right)_{\lambda \epsilon(0 ; \infty)}$, Aczel-Alsina family $\left(\triangle_{\lambda}^{A A}\right)_{\lambda \epsilon(0 ; \infty)}$ and Sugeno-Weber family $\left(\triangle_{\lambda}^{S W}\right)_{\lambda \epsilon(-1 ; \infty)}$ is g-convergent [7].

A large classe of g-convergent $t$-norms, in terms of the generators of strict $t$-norms is discribed in [7] (also see [6], Ch.1.8).

Bhaskar and Lakshmikantham [2], Lakshmikantham and Ćirić [9] gave some coupled fixed point theorems. Coupled fixed point theorem under contraction conditions given by Sedghi and al [17] are of great importance in the theory of fixed points in fuzzy metric spaces. Fang [5] proved a result for compatible and weakly compatible mappings under $\varphi$-contractive conditions in fuzzy metric spaces which provide a tool to Xin-Qi Hu [20] to prove a result, which is actually a generalization of the result of Sedghi [17].

In this paper, firstly we prove some common coupled fixed point theorems for contractive mappings in Menger metric spaces under geometrically convergent t-norms. At the end, we prove common fixed point theorems for pairs of weakly compatible mappings, which generalize the results of Jian-Zhong Xiao and al (2011). The main result is supported by a suitable example.

\section{Preliminaries}

We now state some basic concepts and results which will be used. In the standard notation, suppose that $\mathbb{R}=(-\infty,+\infty), \mathbb{R}^{+}=[0,+\infty), \overline{\mathbb{R}}=\mathbb{R} \cup\{-\infty,+\infty\}$ and $\mathbb{Z}^{+}$be the set of positive integers.

A function $F: \overline{\mathbb{R}} \rightarrow[0,1]:$ is called a distribution function if it is non decreasing and left continuous with $F(-\infty)=F(+\infty)=1$.

The class of all distribution functions is denoted by $D_{\infty}$.

Suppose that $D=\left\{F \in D_{\infty}\right.$. : inf $\left.F D_{\infty}^{+}(t)=0, \sup F(t)=1\right\}, D_{\infty}^{+}=\left\{F \in D_{\infty}: F(0)=0\right\}$ and $D^{+}=D \cap D_{\infty}^{+}(\operatorname{cf}[1,17])$. 
A special element of $D^{+}$is the heaviside function $H$ defined by:

$$
H(t)= \begin{cases}1, & t>0 \\ 0, & t \leq 0\end{cases}
$$

Definition 2.1. ([12]). Afunction $\Delta:[0,1] \times[0,1] \rightarrow[0,1]$ is called a triangular norm (for short, $a$ $t$-norm) if the following conditions are satisfied for any $a, b, c, d \in[0,1]$;

$(\Delta-1) \quad \Delta(a, 1)=a$

$(\Delta-2) \quad \Delta(a, b)=\Delta(b, a)$;

$(\Delta-3) \Delta(a, b) \geq \Delta(c, d)$, for $a \geq c, b \geq d$;

$(\Delta-4) \Delta(\Delta(a, b), c)=\Delta(a, \Delta(b, c))$.

Two exemples of $t$-norm are $\Delta_{M}(a, b)=\min \{a, b\}$ and $\Delta_{P}(a, b)=a b$.

It is evident that, as regards the point wise ordering, $\Delta \leq \Delta_{M}$ for each $t$-norm $\Delta$.

Definition 2.2. ([11, 12]). A triplet $(X, F, \Delta)$ is called a generalised Menger probabilistec metric space if $X$ is a non-empty set, $\Delta$ is t-norm and $F$ is a mapping from $X \times X$ into $D_{\infty}^{+}$satisfying the following condition $\left(F(x, y)\right.$ for $x, y \in X$ is denoted by $\left.F_{x, y}\right)$ :

(MS-1) $F_{x, y}(t)=H(t)$ for all $t \in \mathbb{R}$ if and only if $x=y$;

(MS-2) $F_{x, y}(t)=F_{y, x}(t)$ for all $x, y \in X$ and $t \in \mathbb{R}$

(MS-3) $\quad F_{x, y}(t+s) \geq \triangle\left(F_{x, z}(t), F_{z, y}(s)\right)$ for all $x, y, z \in X$ and $t, s \in \mathbb{R}^{+}$. A Menger probabilistec metric space (for short, a Menger PM-space) is a generalized Menger space with $F(X \times X) \in$ $D^{+}$.

Schweizer and al $[15,16]$ point out that if the t-norm $\triangle$ of a Menger PM-space satisfies the condition $\sup _{0<a<1} \Delta(a, a)=1$, then $(X, F, \Delta)$ is a first countable hausdroff topologicol space in the $(\varepsilon, \lambda)$-topology $\tau$, i.e, the family of sets

$$
\left\{U_{x}(\varepsilon, \lambda): \varepsilon>0, \lambda \in[0,1],(x \in X)\right\}
$$

is the base of neighborhoods of point $x$ for $\tau$, where $U_{x}(\varepsilon, \lambda)=\left\{y \in X: F_{x, y}(\varepsilon)>1-\lambda\right\}$.

By virtue of this topology $\tau$ a sequence $\left\{x_{n}\right\}$ in $(X, F, \Delta)$ is said to be convergent to $x$ (we write $x_{n} \rightarrow x$ or $\left.\lim _{n \rightarrow \infty} x_{n}=x\right)$ if $\lim _{n \rightarrow \infty} F_{x_{n}, x}(t)=1$ for all $t>0 ;\left\{x_{n}\right\}$ is called a Cauchy sequences in $(X, F, \Delta)$ if for any given $\varepsilon>0$ and $\lambda \in[0,1]$, there exists $N=N(\varepsilon, \lambda) \in \mathbb{Z}^{+}$such that $F_{x_{n}, x_{m}}(\varepsilon)>1-\lambda$, whenever $n, m \geq N,(X, F, \Delta)$ is said to be complete if each Cauchy sequence in $X$ is convergent to some point in $X$. In the sequel,we will always assume that $(X, F, \Delta)$ is a Menger space with the $(\varepsilon, \lambda)$-topology.

Lemma 2.1. Let $(X, d)$ be a usual metric space. Define a mapping $F: X \times X \rightarrow D^{+}$by

$$
F_{x, y}(t)=H(t-d(x, y)), \text { for } x, y \in X \text { and } t>0 .
$$

Then $\left(X, F, \Delta_{m}\right)$ is a Menger PM-space; it is called the induced Menger PM-space by $(X, d)$ and it is complete if $(X, d)$ is complete.

An arbitrary t-norme can be extended (by $(\Delta-3))$ in a unique way to an n-ary operation.For $\left(a_{1}, a_{2}, \ldots, a_{n}\right) \in[0,1]^{n}\left(n \in \mathbb{Z}^{+}\right)$, the valued $\Delta^{n}\left(a_{1}, a_{2}, \ldots, a_{n}\right)$ is defined by $\Delta^{1}\left(a_{1}\right)=a_{1}$ and $\Delta^{n}$ $\left(a_{1}, a_{2}, \ldots, a_{n}\right)=\Delta\left(\Delta^{n-1}\left(a_{1}, a_{2}, \ldots, a_{n-1}\right), a_{n}\right)$.

For each $a \in[0,1]$, the sequence $\left\{\Delta^{n}(a)\right\}_{n=1}^{\infty}$ is defined by $\Delta^{1}(a)=a$ and $\Delta^{n}(a)=$ $\Delta\left(\Delta^{n-1}(a), a\right)$. 
Definition 2.3. A t-norm $\Delta$ is said to be of H-type if the sequence of functions $\left\{\Delta^{n}(a)\right\}_{n=1}^{\infty}$ is equicontinuous at $a=1$.

The t-norm $\Delta_{m}$ is a trivial example of a t-norm of H-type, but there are $\mathrm{t}$-norms $\Delta$ of H-type with $\Delta \neq \Delta_{m}$. It is easy to see that if $\Delta$ is of H-type, then $\Delta$ satisfies $\sup _{0<a<1} \Delta(a, a)=1$.

Lemma 2.2. Let $(X, F, \Delta)$ be a Menger PM-space.For each $\lambda \in(0,1]$, define a function $d_{\lambda}: X \times X \rightarrow$ $\mathbb{R}^{+}$by

$$
d_{\lambda}(x, y)=\inf \left\{t>0: F_{x, y}(t)>1-\lambda\right\} .
$$

Then the following statements hold:

(1) $d_{\lambda}(x, y)<t$ if and only if $F_{x, y}(t)>1-\lambda$;

(2) $d_{\lambda}(x, y)=d_{\lambda}(y, x)$ for all $x, y \in X$ and $\lambda \in(0,1]$;

(3) $d_{\lambda}(x, y)=0$ for all $\lambda \in(0,1]$ if and only if $x=y$.

Lemma 2.3. Let $(X, F, \Delta)$ be a Menger PM-space, and let $\left\{d_{\lambda}\right\}_{\lambda \in(0,1]}$ be a family of pseudo-metrics on $X$ defined by (1.1).

If $\Delta$ is a t-norm of H-type, then for each $\lambda \in(0,1]$, there exists $\mu \in(0, \lambda]$ such that for each $m \in \mathbb{Z}^{+}$,

$$
d_{\lambda}\left(x_{0}, x_{m}\right) \leq \sum_{i=0}^{m-1} d_{\mu}\left(x_{i}, x_{i+1}\right), \text { for all } x_{0}, x_{1}, \ldots, x_{m} \in X
$$

Lemma 2.4. Suppose that $F \in D^{+}$. For each $n \in \mathbb{Z}^{+}$, let $F_{n}: \mathbb{R} \rightarrow[0,1]$ be non-decreasing, and $g_{n}:(0,+\infty) \rightarrow(0,+\infty)$ satisfy $\lim _{n \rightarrow+\infty} g_{n}(t)=0$ for any $t>0$.If

$$
F_{n}\left(g_{n}(t)\right) \geq F(t), \forall t>0
$$

then $\lim _{n \rightarrow+\infty} F_{n}(t)=1$, for any $t>0$.

Definition 2.4. ([5]). An element $x \in X$ is called a common fixed point of the mappings $f: X \times X \rightarrow$ $X$ and $g: X \rightarrow X$ if

$$
x=f(x, x)=g(x)
$$

Definition 2.5. ([10]). An element $(x, y) \in X \times X$ is called

(i) a coupled fixed point of the mapping $f: X \times X \rightarrow X$ if

$$
f(x, y)=x ; f(y, x)=y \text {. }
$$

(ii) a coupled coincidence point of the mappings $f: X \times X \rightarrow X$ and $g: X \rightarrow X$ if

$$
f(x, y)=g(x) ; f(y, x)=g(y)
$$

(iii) a common coupled fixed point of the mappings $f: X \times X \rightarrow X$ and $g: X \rightarrow X$ if

$$
x=f(x, y)=g(x) ; y=f(y, x)=g(y)
$$

In [1], Abbas and al introduced the concept of weakly compatible mappings, Here we give a similar concept in Menger metric spaces as follows:

Definition 2.6. Let $(X, F, \Delta)$ be a Menger metric space and let $f: X \times X \rightarrow X$ and $g: X \rightarrow X$ be two mappings $f$ and $g$ are said to be weakly compatible (or w-compatible) if they commute at their coupled coincidence points, i.e, if $(x, y)$ is a coupled coincidence point of $f$ and $g$, then

$$
g(f(x, y))=f(g(x), g(y)), g(f(y, x))=f(g(y), g(x))
$$


Definition 2.7. ([8] ) Let $A: X \times X \rightarrow X, B: X \times X \rightarrow X, T: X \rightarrow X, S: X \rightarrow X$ be four mappings. Then, the pairs $(B, S)$ and $(A, T)$ are said to have common coupled coincidence point if there exists $a, b$ in $X$ such that

$$
B(a, b)=S(a)=T(a)=A(a, b) \text { and } B(b, a)=S(b)=T(b)=A(b, a) .
$$

\section{Main Results}

We now give our main result which provides a common coupled fixed point theorems for contractive mappings in Menger metric spaces under geometrically convergent $t$-norms.

Theorem 3.1. Let $(X, F, \Delta)$ be a Menger metric space with $\Delta$ is a g-convergent $t$-norm. Let $A$ : $X \times X \rightarrow X, B: X \times X \rightarrow X, T: X \rightarrow X$ and $S: X \rightarrow X$ be four mappings satisfying the following condition

(1) $A(X \times X) \subseteq T(X), B(X \times X) \subseteq S(X)$

(2) There exists $k \in(0,1)$ such that

$$
F_{A(x, y), B(u, v)}(k t) \geq \operatorname{Min}\left(F_{S x, T u}(t), F_{S y, T v}(t)\right)
$$

for all $x, y, u, v \in X$ and $t>0$

(3) The pairs $(A, S)$ and $(B, T)$ are weakly compatible.

(4) One of the subspaces $A(X \times X)$ or $T(X)$ and one of $B(X \times X)$ or $S(X)$ are complete.

If there exists $\alpha>0$ and $x_{0}, y_{0} \in X$ such that

$$
\sup _{t>0} t^{\alpha}\left(1-F_{S x_{0}, A\left(x_{0}, y_{0}\right)}(t)\right)<\infty,
$$

and

$$
\sup _{t>0} t^{\alpha}\left(1-F_{S y_{0}, A\left(y_{0}, x_{0}\right)}(t)\right)<\infty .
$$

Then there exists a unique point $a$ in $X$ such that $A(a, a)=S(a)=T(a)=B(a, a)=a$.

Proof. For arbitrary $x_{0}, y_{0}$ in $X$, by $(1)$, we can choose $x_{1}, y_{1}$ in $X$ such that $T\left(x_{1}\right)=A\left(x_{0}, y_{0}\right)$, $T\left(y_{1}\right)=A\left(y_{0}, x_{0}\right)$.

Again by (1), we can choose $x_{2}, y_{2}$ in $X$ such that $S\left(x_{2}\right)=B\left(x_{1}, y_{1}\right), S\left(y_{2}\right)=A\left(y_{1}, x_{1}\right)$. Continuing in this way, we can construct two sequences $\left\{Z_{n}\right\}$ and $\left\{Z_{n}\right\}$ in $X$ such that

$$
\begin{aligned}
& \left\{\begin{array}{l}
Z_{2 n+1}=A\left(x_{2 n}, y_{2 n}\right)=T\left(x_{2 n+1}\right) \\
Z_{2 n+2}=B\left(x_{2 n+1}, y_{2 n+1}\right)=S\left(x_{2 n+2}\right)
\end{array}\right. \\
& \left\{\begin{array}{l}
Z_{2 n+1}=A\left(y_{2 n}, x_{2 n}\right)=T\left(y_{2 n+1}\right) \\
Z_{2 n+2}=B\left(y_{2 n+1}, x_{2 n+1}\right)=S\left(y_{2 n+2}\right)
\end{array}\right.
\end{aligned}
$$

We divide the proof into 6 steps.

Step 1 : We show that $\left\{Z_{n}\right\}$ and $\left\{Z_{n}\right\}$ are Cauchy sequences. Indeed, let $\beta>0$. be such that

$$
t^{\alpha}\left(1-F_{S x_{0}, A\left(x_{0}, y_{0}\right)}(t)\right) \leq \beta
$$


and

for all $t>0$. Then

$$
t^{\alpha}\left(1-F_{S y_{0}, A\left(y_{0}, x_{0}\right)}(t)\right) \leq \beta
$$

$$
F_{S x_{0}, T x_{1}}\left(\frac{1}{t^{n}}\right)>1-\beta\left(t^{\alpha}\right)^{n} \text { and } F_{S y_{0}, T y_{1}}\left(\frac{1}{t^{n}}\right)>1-\beta\left(t^{\alpha}\right)^{n} \text { for every } t>0 \text { and } n \in N .
$$

If $t>0$ and $\varepsilon \in(0,1)$ are given, we choose $\mu$ in interval $(k, 1)$ such that

$$
\Delta_{i=n+1}^{\infty}\left(1-\left(\mu^{\alpha}\right)^{i}\right)>1-\varepsilon \text { and } \delta=\frac{k}{\mu} .
$$

As $\delta \in(0,1)$, we can find $n_{1}\left(=n_{1}(t)\right)$ such that $\sum_{n=n_{1}}^{\infty} \delta^{n}<t$.

Condition (3.1) implies that, for all $s>0$,

$$
F_{T x_{1}, S x_{2}}(k s)=F_{A\left(x_{0}, y_{0}\right), B\left(x_{1}, y_{1}\right)}(k s) \geq \operatorname{Min}\left(F_{S x_{0}, T x_{1}}(s), F_{S y_{0}, T y_{1}}(s)\right),
$$

and

$$
F_{T y_{1}, S y_{2}}(k s)=F_{A\left(y_{0}, x_{0}\right), B\left(y_{1}, x_{1}\right)}(k s) \geq \operatorname{Min}\left(F_{S x_{0}, T x_{1}}(s), F_{S y_{0}, T y_{1}}(s)\right) .
$$

It follows by induction that

$$
F_{Z_{n}, Z_{n+1}}\left(k^{n} s\right) \geq \operatorname{Min}\left(F_{S x_{0}, T x_{1}}(s), F_{S y_{0}, T y_{1}}(s)\right)
$$

and

$$
F_{Z_{n}, Z_{n+1}}\left(k^{n} s\right) \geq \operatorname{Min}\left(F_{S x_{0}, T x_{1}}(s), F_{S y_{0}, T y_{1}}(s)\right)
$$

for all $n \in N$. Then for all $n \geq n_{1}$ and $m \in N$ we obtain

$$
\begin{aligned}
F_{Z_{n}, Z n+m}(t) & \geq F_{Z_{n}, Z n+m}\left(\sum_{i=n_{1}}^{\infty} \delta^{i}\right) \\
& \geq F_{Z_{n}, Z n+m}\left(\sum_{i=n}^{n+m-1} \delta^{i}\right) \\
& \geq \Delta_{i=n}^{n+m-1}\left(F_{Z_{i}, Z_{i+1}}\left(\delta^{i}\right)\right) \\
& \geq \Delta_{i=n}^{n+m-1}\left(\Delta\left(F_{S x_{0}, T x_{1}}\left(\frac{1}{\mu^{i}}\right), F_{S y_{0}, T y_{1}}\left(\frac{1}{\mu^{i}}\right)\right)\right) \\
& \geq \Delta_{i=n}^{n+m-1}\left(1-\beta \mu^{\alpha i}\right) .
\end{aligned}
$$

If we choose $l_{0} \in N$ such that $\beta \mu^{\alpha l_{0}} \leq \mu^{\alpha}$, then $1-\beta\left(\mu^{\alpha}\right)^{n+l_{0}} \geq 1-\left(\mu^{\alpha}\right)^{n+1}$, for all $n$. Thus,

$$
F_{Z_{n+l_{0}}, Z_{n+l_{0}+m}}(t) \geq \Delta_{i=n+1}^{\infty}\left(1-\left(\mu^{\alpha}\right)^{i}\right)>1-\varepsilon,
$$

for every $n \geq n_{1}$ and $m \in N$, hence $\left\{Z_{2 n+1}^{\prime}\right\}$ is a Cauchy sequence. Similarly one can show that $\left\{Z_{n}\right\}$ is a Cauchy sequence.

Step 2 : We show that

$$
T(a)=B(a, b), T(b)=B(a, b) \text { and } S(a)=A(a, b), S(b)=A(b, a) .
$$


Without loss of generality, assume that $T(X)$ and $S(X)$ are complete. Now, $\left\{Z_{2 n+1}\right\},\left\{Z_{2 n+2}\right\}$ and $\left\{Z_{2 n+1}^{\prime}\right\},\left\{Z_{2 n+2}\right\}$ being respective subsequenes of Cauchy sequences $\left\{Z_{n}\right\}$ and $\left\{Z_{n}^{\prime}\right\}$ are also Cauchy.

Since $T(X)$ is complete, so there exists $a, b$ in $X$ such that:

$$
\left\{Z_{2 n+1}\right\} \rightarrow a \text { and }\left\{Z_{2 n+1}^{\prime}\right\} \rightarrow b
$$

Again convergence of the subsequences $\left\{Z_{2 n+1}\right\}$ and $\left\{Z_{2 n+1}\right\}$ implies the convergence of original Cauchy sequences $\left\{Z_{n}\right\}$ and $\left\{Z_{n}\right\}$ respectively such that

$$
\left\{Z_{n}\right\} \rightarrow a \text { and }\left\{Z_{n}^{\prime}\right\} \rightarrow b
$$

It follows that the sequences $\left\{Z_{n}\right\},\left\{Z_{2 n+1}\right\},\left\{Z_{2 n+2}\right\}$ converge to $a$ and $\left\{Z_{n}\right\},\left\{Z_{2 n+1}^{\prime}\right\}\left\{Z_{2 n+2}^{\prime}\right\}$ converge to $b$.

Now $a, b \in T(X)$ implies the existence of $p, q \in X$ such that $T(p)=a, T(q)=b$, so that we have

$$
\begin{aligned}
& \lim _{n \rightarrow \infty} Z_{2 n+1}=\lim _{n \rightarrow \infty} A\left(x_{2 n}, y_{2 n}\right)=\lim _{n \rightarrow \infty} T\left(x_{2 n+1}\right)=a=T(p) \\
& \lim _{n \rightarrow \infty} Z_{2 n+2}=\lim _{n \rightarrow \infty} B\left(x_{2 n+1}, y_{2 n+1}\right)=\lim _{n \rightarrow \infty} S\left(x_{2 n+2}\right)=a=T(p),
\end{aligned}
$$

and

$$
\begin{aligned}
& \lim _{n \rightarrow \infty} Z_{2 n+1}^{\prime}=\lim _{n \rightarrow \infty} A\left(y_{2 n}, x_{2 n}\right)=\lim _{n \rightarrow \infty} T\left(y_{2 n+1}\right)=b=T(q) \\
& \lim _{n \rightarrow \infty} Z_{2 n+2}^{\prime}=\lim _{n \rightarrow \infty} B\left(y_{2 n+1}, x_{2 n+1}\right)=\lim _{n \rightarrow \infty} S\left(y_{2 n+2}\right)=b=T(q),
\end{aligned}
$$

From condition (2),

$$
F_{A\left(x_{2 n}, y_{2 n}\right), B(p, q)}(k t) \geq \operatorname{Min}\left(F_{S\left(x_{2 n}\right), T(p)}(t), F_{S\left(y_{2 n}\right), T(q)}(t)\right) .
$$

Letting $n \rightarrow \infty$, we get

$$
F_{T(p), B(p, q)}(k t) \geq 1 \text { this implies } T(p)=B(p, q)=a .
$$

Similarly $T(q)=B(q, p)=b$.

Since the pair $(B, T)$ are weakly compatible, so that $T(p)=B(p, q)=a$ implies $T(a)=$ $B(a, b)$, similarly, $T(b)=B(b, a)$.

Again, since $S(X)$ is complete, so that $a, b \in S(X)$, which implies the existence of $r, s$ in $X$, so that: $S(r)=a, S(s)=b$.

from inequality (3.1), we get

$$
F_{A(r, s), B\left(x_{2 n+1}, y_{2 n+1}\right)}(k t) \geq \operatorname{Min}\left(F_{S(r), T\left(x_{2 n+1}\right)}(t), F_{S(s), T\left(y_{2 n+1}\right)}(t)\right)
$$

Letting $n \rightarrow \infty$, we get

$$
F_{A(r, s), a}(k t) \geq 1 \text { implies } A(r, s)=a=S(r)
$$

Similarly, $A(s, r)=b=S(s)$.

Since the pair $(A, S)$ are weakly compatible, it follows that:

$$
A(a, b)=S(a) \text { and } A(b, a)=S(b) \text {. }
$$


Step 3 : Next we show $S(a)=T(a)$ and $S(b)=T(b)$.

From inequality (3.1):

$$
F_{A(a, b), B(a, b)}(k t) \geq \operatorname{Min}\left(F_{S(a), T(a)}(t), F_{S(b), T(b)}(t)\right)
$$

and similarly

$$
F_{A(b, a), B(b, a)}(k t) \geq \operatorname{Min}\left(F_{S(a), T(a)}(t), F_{S(b), T(b)}(t)\right)
$$

Thus

$$
\operatorname{Min}\left\{F_{S(a), T(a)}(t), F_{S(a), T(a)}(t)\right\} \geq \operatorname{Min}\left\{F_{S(a), T(a)}\left(\frac{t}{k^{n}}\right), F_{S(b), T(b)}\left(\frac{t}{k^{n}}\right)\right\}
$$

for all $n \in N$ implying

$$
\operatorname{Min}\left\{F_{S(a), T(a)}(t), F_{S(b), T(b)}(t)\right\}=1
$$

It follows that

$$
F_{S(a), T(a)}(t)=1=F_{S(b), T(b)}(t) \text { for all } t>0 .
$$

Whence $S(a)=T(a)$ and $S(b)=T(b)$, as claimed.

Therefore,

$$
S(a)=A(a, b)=B(a, b)=T(a) \text { and } S(b)=A(b, a)=B(b, a)=T(b) .
$$

Step 4 : We next show that

$$
S(a)=a \text { and } S(b)=b .
$$

Indeed, letting $n \rightarrow \infty$ in the inequality

$$
F_{A\left(x_{2 n}, y_{2 n}\right), B(a, b)}(k t) \geq \operatorname{Min}\left(F_{S\left(x_{2 n}\right), T(a)}(t), F_{S\left(y_{2 n}\right), T(b)}(t)\right) .
$$

We get

$$
F_{a, S(a)}(k t) \geq \operatorname{Min}\left(F_{a, S(a)}(t), F_{b, S(b)}(t)\right)
$$

and similarly

$$
F_{b, S(b)}(k t) \geq \operatorname{Min}\left(F_{a, S(a)}(t), F_{b, S(b)}(t)\right)
$$

Thus

$$
\operatorname{Min}\left\{F_{a, S(a)}(t), F_{b, S(b)}(t)\right\} \geq \operatorname{Min}\left\{F_{a, S(a)}\left(\frac{t}{k^{n}}\right), F_{b, S(b)}\left(\frac{t}{k^{n}}\right)\right\},
$$

for all $n \in N$, implies

$$
\operatorname{Min}\left\{F_{a, S(a)}(t), F_{b, S(b)}(t)\right\}=1
$$

It follows that

$$
F_{a, S(a)}(t)=1=F_{b, S(b)}(t) \text { for all } t>0 .
$$

Whence $S(a)=a$ and $S(b)=b$. There are :

$$
B(a, b)=S(a)=a=T(a)=A(a, b) \text { and } B(b, a)=S(b)=b=T(b)=A(b, a) .
$$

Step 5 : We shall that $a=b$. Indeed, letting $n \rightarrow \infty$ in the inequality

$$
F_{A\left(x_{2 n}, y_{2 n}\right), B\left(y_{2 n+1}, x_{2 n+1}\right)}(k t) \geq \operatorname{Min}\left(F_{S\left(x_{2 n}\right), T\left(y_{2 n+1}\right)}(t), F_{S\left(y_{2 n}\right), T\left(x_{2 n+1}\right)}(t)\right)
$$


We get

$$
F_{a, b}(k t) \geq \operatorname{Min}\left(F_{a, b}(t), F_{b, a}(t)\right)
$$

It follows that $F_{a, b}(k t) \geq F_{a, b}(t)$ for all $t>0$, and so $a=b$.

Hence:

$$
B(a, a)=S(a)=a=T(a)=A(a, a) .
$$

Step 6: We show that the fixed point is unique.

Let $z, w$ be common fixed points for $A, B, S$ and $T$, then from (3.1), we obtain

$$
F_{A(z, z), B(w, w)}(k t) \geq \operatorname{Min}\left(F_{S z, T w}(t), F_{S z, T w}(t)\right) .
$$

That is $F_{z, w}(k t) \geq F_{z, w}(t)$ for all $t>0$ implying $z=w$.

If the t-norm $\Delta$ is of Hadžić-type, then the conditions

$$
\sup _{t>0} t^{\alpha}\left(1-F_{S x_{0}, A\left(x_{0}, y_{0}\right)}(t)\right)<\infty,
$$

and

$$
\sup _{t>0} t^{\alpha}\left(1-F_{S y_{0}, A\left(y_{0}, x_{0}\right)}(t)\right)<\infty .
$$

can be dropped, so we have the following result :

Corollary 3.1. Let $(X, F, \Delta)$ be a Menger metric space with $\Delta$ is a t-norm of H-type. Let $A: X \times X \rightarrow$ $X, B: X \times X \rightarrow X, T: X \rightarrow X, S: X \rightarrow X$ be four mappings satisfying the following condition

(1) $A(X \times X) \subseteq T(X), B(X \times X) \subseteq S(X)$

(2) There exists $k \in(0,1)$ such that

$$
F_{A(x, y), B(u, v)}(k t) \geq \operatorname{Min}\left(F_{S x, T u}(t), F_{S y, T v}(t)\right)
$$

for all $x, y, u, v \in X$ and $t>0$

(3)The pairs $(A, S)$ and $(B, T)$ are w-compatible.

(4) One of the subspaces $A(X \times X)$ or $T(X)$ and one of $B(X \times X)$ or $S(X)$ are complete.

Then there exists a unique point $a$ in $X$ such that $A(a, a)=S(a)=T(a)=B(a, a)=a$.

Corollary 3.2. Let $(X, F, \Delta)$ be a Menger metric space with $\Delta$ is a t-norm of H-type. Let $A: X \times X \rightarrow$ $X$ be a mapping, and assume that for any $t>0$; there exists $k \in(0,1)$ such that

$$
F_{A(x, y), A(u, v)}(k t) \geq \operatorname{Min}\left(F_{x, u}(t), F_{y, v}(t)\right)
$$

for all $x, y, u, v \in X$.

Suppose that $A(X \times X)$ is complete. Then $A$ has a unique coupled fixed point $a \in X$ such that $A(a, a)=a$.

Jian-Zhong Xiao in [19] proved the following result :

Theorem 3.2. Let $(X, F, \Delta)$ be a complete Menger metric space with $\Delta$ is a t-norm of H-type and $\Delta \geq \Delta_{p}$. Let $\varphi: \mathbb{R}^{+} \rightarrow \mathbb{R}^{+}$be a gauge function such that $\varphi^{-1}(\{0\})=\{0\}$ and $\sum_{n=1}^{\infty} \varphi^{n}(t)<+\infty$ for any $t>0$.Let $A: X \times X \rightarrow X, T: X \rightarrow X$ be two mappings such that

$$
F_{A(x, y), A(u, v)}(\varphi(t)) \geq\left[\Delta\left(F_{T x, T u}(t), F_{T y, T v}(t)\right)\right]^{1 / 2}
$$


for all $x, y, u, v \in X$ and $t>0$,where $A(X \times X) \subseteq T(X), T$ is continuous and commutative with A.Then there exists a unique $u \in X$ such that $u=T u=A(u, u)$.

Now, we prove the following result which generalizes the previous theorem for two pairs of weakly compatible mapings:

Theorem 3.3. Let $(X, F, \Delta)$ be a Menger metric space with $\Delta$ is a t-norm of $H$-type and $\Delta \geq \Delta_{p}$. Let $\varphi: \mathbb{R}^{+} \rightarrow \mathbb{R}^{+}$be a gauge function such that $\varphi^{-1}(\{0\})=\{0\}$ and $\sum_{n=1}^{\infty} \varphi^{n}(t)<+\infty$ for any $t>0$.Let $A: X \times X \rightarrow X, B: X \times X \rightarrow X, T: X \rightarrow X$ and $S: X \rightarrow X$ be four mappings satisfying the following condition

(1) $A(X \times X) \subseteq T(X), B(X \times X) \subseteq S(X)$

(2)

$$
F_{A(x, y), B(u, v)}(\varphi(t)) \geq\left[\Delta\left(F_{S x, T u}(t), F_{S y, T v}(t)\right)\right]^{1 / 2}
$$

for all $x, y, u, v \in X$ and $t>0$

(3)The pairs $(A, S)$ and $(B, T)$ are w-compatible.

(4) One of the subspaces $A(X \times X)$ or $T(X)$ and one of $B(X \times X)$ or $S(X)$ are complete.

Then there exists a unique point $a \in X$ such that $A(a, a)=S(a)=T(a)=B(a, a)=a$.

Proof. Step 1: We show that $\left\{Z_{n}\right\}$ and $\left\{Z_{n}\right\}$ are Cauchy sequences.

By condition (1), we can construct two sequences $\left\{Z_{n}\right\}$ and $\left\{Z_{n}\right\}$ in $X$ such that

Suppose that $t>0$. From (3.2), we have

$$
\begin{aligned}
& \left\{\begin{array}{l}
Z_{2 n+1}=A\left(x_{2 n}, y_{2 n}\right)=T\left(x_{2 n+1}\right) \\
Z_{2 n+2}=B\left(x_{2 n+1}, y_{2 n+1}\right)=S\left(x_{2 n+2}\right)
\end{array}\right. \\
& \left\{\begin{array}{l}
Z_{2 n+1}=A\left(y_{2 n}, x_{2 n}\right)=T\left(y_{2 n+1}\right) \\
Z_{2 n+2}=B\left(y_{2 n+1}, x_{2 n+1}\right)=S\left(y_{2 n+2}\right)
\end{array}\right.
\end{aligned}
$$

$$
\begin{array}{rlc}
F_{Z_{n}, Z_{n+1}}(\varphi(t)) & = & F_{T x_{n}, S x_{n+1}}(\varphi(t)) \\
& = & F_{A\left(x_{n-1}, y_{n-1}\right), B\left(x_{n}, y_{n}\right)}(\varphi(t)) \\
& \geq & {\left[\Delta\left(F_{S x_{n-1}, T x_{n}}(t), F_{S y_{n-1}, T y_{n}}(t)\right)\right]^{1 / 2}} \\
& = & {\left[\Delta\left(F_{Z_{n-1}, Z_{n}}(t), F_{Z_{n-1}^{\prime}, Z_{n}^{\prime}}(t)\right)\right]^{1 / 2}} \\
F_{Z_{n}^{\prime}, Z_{n+1}^{\prime}}(\varphi(t)) & = & F_{T y_{n}, S y_{n+1}}(\varphi(t)) \\
& = & F_{A\left(y_{n-1}, x_{n-1}\right), B\left(y_{n}, x_{n}\right)}(\varphi(t)) \\
& \geq & {\left[\Delta\left(F_{S y_{n-1}, T y_{n}}(t), F_{S x_{n-1}, T x_{n}}(t)\right)\right]^{1 / 2}} \\
& = & {\left[\Delta\left(F_{Z_{n-1}^{\prime}, Z_{n}^{\prime}}(t), F_{Z_{n-1}, Z_{n}}(t)\right)\right]^{1 / 2}}
\end{array}
$$

Suppose that $G_{n}(t)=\left[\Delta\left(F_{Z_{n-1}^{\prime}, Z_{n}^{\prime}}(t), F_{Z_{n-1}, Z_{n}}(t)\right)\right]^{1 / 2}$. Then, operating by t-norm $\Delta$ on (3.3) and (3.4), from the condition $\Delta \geq \Delta_{p}$, we obtain

$$
G_{n+1}(\varphi(t)) \geq\left[\Delta\left(G_{n}(t), G_{n}(t)\right)\right]^{1 / 2} \geq\left[G_{n}(t) G_{n}(t)\right]^{1 / 2}=G_{n}(t)
$$


Thus, it follows from (3.3) - (3.5) that

$$
\begin{gathered}
F_{Z_{n}, Z_{n+1}}\left(\varphi^{n}(t)\right) \geq G_{n}\left(\varphi^{n-1}(t)\right) \geq \ldots \geq G_{1}(t) \quad \text { and. } \\
F_{Z_{n}^{\prime}, Z_{n+1}^{\prime}}\left(\varphi^{n}(t)\right) \geq G_{n}\left(\varphi^{n-1}(t)\right) \geq \ldots \geq G_{1}(t) .
\end{gathered}
$$

In the next step we show that $\left\{Z_{n}\right\}$ is a Cauchy sequence. For each $\lambda \in(0,1]$, suppose that

$$
D_{\lambda}=\inf \left\{t>0: G_{1}(t)>1-\lambda\right\} \text {. }
$$

Then, $G_{1}\left(D_{\lambda}+1\right)>1-\lambda$. From (3.6) we see that $F_{Z_{n}, Z_{n+1}}\left(\varphi^{n}\left(D_{\lambda}+1\right)\right)>1-\lambda$. By lemma 3, we have

$$
d_{\lambda}\left(Z_{n}, Z_{n+1}\right)<\varphi^{n}\left(D_{\lambda}+1\right) \text {, for each } \lambda \in(0,1] .
$$

By Lemma 3, for each $\lambda \in(0,1]$ there exists $\mu \in(0, \lambda]$ such that

$$
d_{\lambda}\left(Z_{n}, Z_{m}\right) \leq \sum_{i=0}^{m-1} d_{\mu}\left(Z_{i}, Z_{i+1}\right), \text { for all } m, n \in \mathbb{Z}^{+} \text {with } m>n \text {. }
$$

Suppose that $\varepsilon>0$ and $\lambda \in(0,1]$ are given. Since $\sum_{n=1}^{\infty} \varphi^{n}\left(D_{\lambda}+1\right)<+\infty$, there exists $N \in \mathbb{Z}^{+}$such that $\sum_{i=0}^{m-1} \varphi^{i}\left(D_{\mu}+1\right)<\varepsilon$ for all $m>n \geq N$. Thus, by (3.8) and (3.9), we have $d_{\lambda}\left(Z_{n}, Z_{n+1}\right)<\varepsilon$. Using Lemma 3 , we obtain that $F_{Z_{n}, Z_{m}}(\varepsilon)>1-\lambda$ for all $m>n \geq N$, i.e., $\left\{Z_{n}\right\}$ is a Cauchy sequence. Similarly, from (3.7) we can show that $\left\{Z_{n}^{\prime}\right\}$ is a Cauchy sequence.

Step 2: We show that $T(a)=B(a, b), T(b)=B(b, a)$ and $S(a)=A(a, b), S(b)=A(b, a)$ wirhout loss of generality,assume that $T(X)$ and $S(X)$ are complete. Now $\left\{Z_{2 n+1}\right\},\left\{Z_{2 n+2}\right\}$ and $\left\{Z_{2 n+1}^{\prime}\right\},\left\{Z_{2 n+2}^{\prime}\right\}$ being respective subsequences of Cauchy sequences $\left\{Z_{n}\right\}$ and $\left\{Z_{n}^{\prime}\right\}$ are also Cauchy.

Since $T(X)$ is complete, so there exists $a, b$ in $X$ such that:

$$
\left\{Z_{2 n+1}\right\} \rightarrow a \text { and }\left\{Z_{2 n+1}\right\} \rightarrow b
$$

Again convergence of the subsequences $\left\{Z_{2 n+1}\right\}$ and $\left\{Z_{2 n+1}\right\}$ implies the convergence of original Cauchy sequences $\left\{Z_{n}\right\}$ and $\left\{Z_{n}\right\}$ respectively such that

$$
\left\{Z_{n}\right\} \rightarrow a \text { and }\left\{Z_{n}\right\} \rightarrow b .
$$

It follows that the sequences $\left\{Z_{n}\right\},\left\{Z_{2 n+1}\right\},\left\{Z_{2 n+2}\right\}$ converge to $a$ and $\left\{Z_{n}\right\},\left\{Z_{2 n+1}^{\prime}\right\},\left\{Z_{2 n+2}^{\prime}\right\}$ converge to $b$.

Now $a, b \in T(X)$ implies the existence of $p, q \in X$ such that $T(p)=a, T(q)=b$, so that we have

and

$$
\begin{gathered}
\lim _{n \rightarrow \infty} Z_{2 n+1}=\lim _{n \rightarrow \infty} A\left(x_{2 n}, y_{2 n}\right)=\lim _{n \rightarrow \infty} T\left(x_{2 n+1}\right)=a=T(p) \\
\lim _{n \rightarrow \infty} Z_{2 n+2}=\lim _{n \rightarrow \infty} B\left(x_{2 n+1}, y_{2 n+1}\right)=\lim _{n \rightarrow \infty} S\left(x_{2 n+2}\right)=a=T(p)
\end{gathered}
$$

$$
\begin{aligned}
& \lim _{n \rightarrow \infty} Z_{2 n+1}^{\prime}=\lim _{n \rightarrow \infty} A\left(y_{2 n}, x_{2 n}\right)=\lim _{n \rightarrow \infty} T\left(y_{2 n+1}\right)=b=T(q) \\
& \lim _{n \rightarrow \infty} Z_{2 n+2}^{\prime}=\lim _{n \rightarrow \infty} B\left(y_{2 n+1}, x_{2 n+1}\right)=\lim _{n \rightarrow \infty} S\left(y_{2 n+2}\right)=b=T(q) .
\end{aligned}
$$


Since $\sum_{n=1}^{\infty} \varphi^{n}(t)<+\infty$, we have $\lim _{n \rightarrow \infty} \varphi^{n}(t)=0$, so there exists $n_{0} \in \mathbb{Z}^{+}$such that $\varphi^{n_{0}}(t)<$ $t$. Thus, from (3.2) we have

$$
\begin{aligned}
F_{T\left(x_{2 n+1}\right), B(p, q)}(t) & \geq F_{T\left(x_{2 n+1}\right), B(p, q)}\left(\varphi^{n_{0}}(t)\right)=F_{A\left(x_{2 n}, y_{2 n}\right), B(p, q)}\left(\varphi^{n_{0}}(t)\right) \\
& \geq\left[\Delta\left(F_{S\left(x_{2 n}\right), T(p)}\left(\varphi^{n_{0}-1}(t)\right), F_{S\left(y_{2 n}\right), T(q)}\left(\varphi^{n_{0}-1}(t)\right)\right)\right]^{1 / 2} \\
& \geq\left[F_{S\left(x_{2 n}\right), T(p)}\left(\varphi^{n_{0}-1}(t)\right) F_{S\left(y_{2 n}\right), T(q)}\left(\varphi^{n_{0}-1}(t)\right)\right]^{1 / 2}
\end{aligned}
$$

Letting $n \rightarrow \infty$ in (3.12), we have $\lim _{n \rightarrow \infty} T\left(x_{2 n+1}\right)=B(p, q)$. By (3.10), $T(p)=B(p, q)=a$. Similarly, we can show that $T(q)=B(q, p)=b$.

Since the pair $(B, T)$ are weakly compatible, so that $T(p)=B(p, q)=a$ implies $T(a)=$ $B(a, b)$, similarly, $T(b)=B(b, a)$.

Again, since $S(X)$ is complete, so that $a, b \in S(X)$, which implies the existence of $r, s$ in $X$, so that: $S(r)=a, S(s)=b$.

Since $\sum_{n=1}^{\infty} \varphi^{n}(t)<+\infty$,we have $\lim _{n \rightarrow \infty} \varphi^{n}(t)=0$, and so there exists $n_{0} \in \mathbb{Z}^{+}$such that $\varphi^{n_{0}}(t)<t$. Thus, from (3.2) we get

$$
\begin{aligned}
F_{A(r, s), S\left(x_{2 n+2}\right)}(t) & \geq F_{A(r, s), S\left(x_{2 n+2}\right)}\left(\varphi^{n_{0}}(t)\right)=F_{A(r, s), B\left(x_{2 n+1}, y_{2 n+1}\right)}\left(\varphi^{n_{0}}(t)\right) \\
& \geq\left[\Delta\left(F_{S(r), T\left(x_{2 n+1}\right)}\left(\varphi^{n_{0}-1}(t)\right), F_{S(s), T\left(y_{2 n+1}\right)}\left(\varphi^{n_{0}-1}(t)\right)\right)\right]^{1 / 2} \\
& \geq\left[F_{S(r), T\left(x_{2 n+1}\right)}\left(\varphi^{n_{0}-1}(t)\right) F_{S(s), T\left(y_{2 n+1}\right)}\left(\varphi^{n_{0}-1}(t)\right)\right]^{1 / 2}
\end{aligned}
$$

Letting $n \rightarrow \infty$ in (3.13), we have $\lim _{n \rightarrow \infty} S\left(x_{2 n+2}\right)=A(r, s)$. By (3.11), $S(r)=A(r, s)=a$. Similarly, we can show that $S(s)=A(s, r)=b$.

Since the pair $(A, S)$ are weakly compatible, it follows that: $A(a, b)=S(a)$ and $A(b, a)=$ $S(b)$.

Step 3 : We claim that $T a=b, T b=a$ and $S a=b, S b=a$

In fact, from (3.2) we have

$$
\begin{aligned}
F_{T\left(y_{2 n+1}\right), T a}(\varphi(t)) & =F_{A\left(y_{2 n}, x_{2 n}\right), B(a, b)}(\varphi(t)) \\
& \geq\left[\Delta\left(F_{S\left(y_{2 n}\right), T(a)}(t), F_{S\left(x_{2 n}\right), T(b)}(t)\right)\right]^{1 / 2} \\
& \geq\left[F_{S\left(y_{2 n}\right), T(a)}(t) F_{S\left(x_{2 n}\right), T(b)}(t)\right]^{1 / 2} .
\end{aligned}
$$

Similarly, we have

$$
F_{T\left(x_{2 n+1}\right), T b}(\varphi(t)) \geq\left[F_{S\left(x_{2 n}\right), T(b)}(t) F_{S\left(y_{2 n}\right), T a}(t)\right]^{1 / 2}
$$

Suppose that $Q_{n}(t)=F_{S\left(y_{2 n}\right), T(a)}(t) F_{S\left(x_{2 n}\right), T(b)}(t)$. By (3.14) and (3.15), we have $Q_{n}(\varphi(t)) \geq$ $Q_{n-1}(t)$, hence

$$
Q_{n}\left(\varphi^{n}(t)\right) \geq Q_{n-1}\left(\varphi^{n-1}(t)\right) \geq \ldots \geq Q_{0}(t) .
$$

Furthermore, from $(3.14)-(3.16)$ it follows that

$$
F_{T\left(y_{2 n+1}\right), T a}\left(\varphi^{n}(t)\right) \geq\left[Q_{0}(t)\right]^{1 / 2} ; \text { and } F_{T\left(x_{2 n+1}\right), T b}\left(\varphi^{n}(t)\right) \geq\left[Q_{0}(t)\right]^{1 / 2}
$$


It is evident that $\left[Q_{0}(t)\right]^{1 / 2} \in D^{+}$. Since $\lim _{n \rightarrow \infty} \varphi^{n}(t)=0$, from (3.17) and lemma 4 we have

$$
\lim _{n \rightarrow \infty} T\left(y_{2 n+1}\right)=T a \text { and } \lim _{n \rightarrow \infty} T\left(x_{2 n+1}\right)=T b .
$$

This shows that $T a=b$ and $T b=a$. Hence, $B(a, b)=b$ and $B(b, a)=a$.

Similarly, we can show that $S a=b$ and $S b=a$. Hence, $A(a, b)=b$ and $A(b, a)=a$.

Step 4: Now we prove that $a=b$.

By (3.2) we have

$$
\begin{aligned}
F_{a, b}(\varphi(t)) & =F_{A(b, a), B(a, b)}(\varphi(t)) \\
& \geq\left[\Delta\left(F_{S(b), T(a)}(t), F_{S(a), T(b)}(t)\right)\right]^{1 / 2} \\
& \geq F_{a, b}(t) .
\end{aligned}
$$

From (3.18), we have $F_{a, b}\left(\varphi^{n}(t)\right) \geq F_{a, b}(t)$. Using Lemma 2.4 , we have $F_{a, b}(t)=1$, i.e., $a=b$. The uniqueness of $a$ follows from (3.2). So, the proof of Theorem 3.3 is finished.

Theorem 3.4. Let $(X, F, \Delta)$ be a Menger metric space with $\Delta$ is a t-norm of H-type. Let $\varphi: \mathbb{R}^{+} \rightarrow \mathbb{R}^{+}$ be a gauge function such that $\varphi^{-1}(\{0\})=\{0\}, \varphi(t)<t$ and $\lim _{n \rightarrow \infty} \varphi^{n}(t)=+\infty$ for any $t>0$. Let $A: X \times X \rightarrow X, B: X \times X \rightarrow X, T: X \rightarrow X, S: X \rightarrow X$ be four mappings satisfying the following condition

(1) $A(X \times X) \subseteq T(X), B(X \times X) \subseteq S(X)$

(2)

$$
F_{A(x, y), B(u, v)}(t) \geq \min \left\{F_{S x, T u}(\varphi(t)), F_{S y, T v}(\varphi(t))\right\}
$$

for all $x, y, u, v \in X$ and $t>0$

(3)The pairs $(A, S)$ and $(B, T)$ are w-compatible.

(4) One of the subspaces $A(X \times X)$ or $T(X)$ and one of $B(X \times X)$ or $S(X)$ are complete.

Then there exists a unique point $a \in X$ such that $A(a, a)=S(a)=T(a)=B(a, a)=a$.

Proof. Step1: We show that $\left\{Z_{n}\right\}$ and $\left\{Z_{n}\right\}$ are Cauchy sequences.

By condition (1),we can construct two sequences $\left\{Z_{n}\right\}$ and $\left\{Z_{n}^{\prime}\right\}$ in $X$ such that

$$
\begin{aligned}
& \left\{\begin{array}{l}
Z_{2 n+1}=A\left(x_{2 n}, y_{2 n}\right)=T\left(x_{2 n+1}\right) \\
Z_{2 n+2}=B\left(x_{2 n+1}, y_{2 n+1}\right)=S\left(x_{2 n+2}\right)
\end{array}\right. \\
& \left\{\begin{array}{l}
Z_{2 n+1}=A\left(y_{2 n}, x_{2 n}\right)=T\left(y_{2 n+1}\right) \\
Z_{2 n+2}=B\left(y_{2 n+1}, x_{2 n+1}\right)=S\left(y_{2 n+2}\right)
\end{array}\right.
\end{aligned}
$$

Suppose that $t>0$. From (3.19),we have

$$
\begin{array}{rlc}
F_{Z_{n}, Z_{n+1}}(\varphi(t)) & = & F_{T x_{n}, S x_{n+1}}(\varphi(t)) \\
& = & F_{A\left(x_{n-1}, y_{n-1}\right), B\left(x_{n}, y_{n}\right)}(\varphi(t)) \\
& \geq & {\left[F_{S x_{n-1}, T x_{n}}(t) F_{S y_{n-1}, T y_{n}}(t)\right]^{1 / 2}} \\
& = & {\left[F_{Z_{n-1}, Z_{n}}(t) F_{Z_{n-1}^{\prime}, Z_{n}^{\prime}}(t)\right]^{1 / 2}}
\end{array}
$$




$$
\begin{aligned}
& F_{Z_{n}^{\prime}, Z_{n+1}^{\prime}}(\varphi(t))=\quad F_{T y_{n}, S y_{n+1}}(\varphi(t)) \\
& =F_{A\left(y_{n-1}, x_{n-1}\right), B\left(y_{n}, x_{n}\right)}(\varphi(t)) \\
& \geq\left[F_{S y_{n-1}, T y_{n}}(t) F_{S x_{n-1}, T x_{n}}(t)\right]^{1 / 2} \\
& =\left[F_{Z_{n-1}^{\prime}}, Z_{n}^{\prime}(t) F_{Z_{n-1}, Z_{n}}(t)\right]^{1 / 2}
\end{aligned}
$$

Suppose that $P_{n}(t)=\left[F_{Z_{n-1}, Z_{n}}(t) F_{Z_{n-1}^{\prime}, Z_{n}^{\prime}}(t)\right]^{1 / 2}$. Then, (3.20) and (3.21) we obtain $P_{n+1}(\varphi(t)) \geq$ $P_{n}(t)$.This implies that

$$
\begin{aligned}
& F_{Z_{n}, Z_{n+1}}\left(\varphi^{n}(t)\right) \geq P_{n}\left(\varphi^{n-1}(t)\right) \geq \ldots \geq P_{1}(t) \text { and. } \\
& F_{Z_{n}^{\prime}, Z_{n+1}^{\prime}}\left(\varphi^{n}(t)\right) \geq P_{n}\left(\varphi^{n-1}(t)\right) \geq \ldots \geq P_{1}(t) .
\end{aligned}
$$

Since $P_{1}(t)=\left[F_{Z_{0}, Z_{1}}(t) F_{Z_{0}^{\prime}, Z_{1}^{\prime}}(t)\right]^{1 / 2} \in D^{+}$and $\lim _{n \rightarrow \infty} \varphi^{n}(t)=0$ for each $t>0$,by lemma(4) we have

$$
\lim _{n \rightarrow \infty} F_{Z_{n}, Z_{n+1}}(t)=1 \text { and } \lim _{n \rightarrow \infty} F_{Z_{n}^{\prime}, Z_{n+1}^{\prime}}(t)=1
$$

Thus, by (3.24), we have

$$
\lim _{n \rightarrow \infty} P_{n}(t)=1 \text { for all } t>0
$$

We claim that,for any $k \in \mathbb{Z}^{+}$,

$$
F_{Z_{n}, Z_{n+k}}(t) \geq \Delta^{k}\left(P_{n}(t-\varphi(t))\right) \text { and } F_{Z_{n}^{\prime}, Z_{n+k}^{\prime}}(t) \geq \Delta^{k}\left(P_{n}(t-\varphi(t))\right) .
$$

In fact,this is obvious for $k=1$ by (3.20) and (3.21).Assume that (3.26) holds for some $k$.

Since $\varphi(t)<t$.By (3.20), we have

$F_{Z_{n}, Z_{n+1}}(t) \geq F_{Z_{n}, Z_{n+1}}(\varphi(t)) \geq P_{n}(t)$. By (3.19) and (3.26), we have

$$
\begin{aligned}
F_{Z_{n+1}, Z_{n+k+1}}(\varphi(t)) & \geq\left[F_{Z_{n}, Z_{n+k}}(t) F_{Z_{n}^{\prime}, Z_{n+k}^{\prime}}(t)\right]^{1 / 2} \\
& \geq \Delta^{k}\left(P_{n}(t-\varphi(t))\right) .
\end{aligned}
$$

Hence, by the monotonicity of $\Delta$, we have

$$
\begin{aligned}
F_{Z_{n}, Z_{n+k+1}}(t) & =F_{Z_{n}, Z_{n+k+1}}(t-\varphi(t)+\varphi(t)) \\
& \geq \Delta\left(F_{Z_{n}, Z_{n+1}}(t-\varphi(t)), F_{Z_{n+1}, Z_{n+k+1}}(\varphi(t))\right) \\
& \geq \Delta\left(P_{n}(t-\varphi(t)), \Delta^{k}\left(P_{n}(t-\varphi(t))\right)\right)=\Delta^{k+1}\left(P_{n}(t-\varphi(t))\right) .
\end{aligned}
$$

Similarly, we have $F_{Z_{n}^{\prime}, Z_{n+k+1}^{\prime}}(t) \geq \Delta^{k+1}\left(P_{n}(t-\varphi(t))\right)$. Therefor, by induction, (3.26) holds for all $k \in \mathbb{Z}^{+}$. Suppose that $\varepsilon>0$ and $\lambda \in(0,1]$ are given.

By hypothesis, $\Delta$ is a t-norm of $\mathrm{H}$-type; there exists $\delta>0$ such that

$$
\Delta^{k}(s)>1-\lambda, \text { for all } s \in(1-\delta, 1] \text { and } k \in \mathbb{Z}^{+} .
$$

By (3.25), there exists $N \in \mathbb{Z}^{+}$such that $P_{n}(\varepsilon-\varphi(\varepsilon))>1-\delta$ for all $n \geq N$.

Hence, from (3.26) and (3.27) we get 


$$
F_{Z_{n}, Z_{n+k}}(\varepsilon)>1-\lambda \text { and } F_{Z_{n}^{\prime}, Z_{n+k}^{\prime}}(\varepsilon)>1-\lambda, \text { for all } n \geq N ; k \in \mathbb{Z}^{+} .
$$

Therefor, $\left\{Z_{n}\right\}$ and $\left\{Z_{n}^{\prime}\right\}$ are all Cauchy sequences.

Step 2: We show that $T(a)=B(a, b), T(b)=B(b, a)$ and $S(a)=A(a, b), S(b)=A(b, a)$ wirhout loss of generality,assume that $T(X)$ and $S(X)$ are complete.Now $\left\{Z_{2 n+1}\right\},\left\{Z_{2 n+2}\right\}$ and $\left\{Z_{2 n+1}^{\prime}\right\},\left\{Z_{2 n+2}^{\prime}\right\}$ being respective subsequences of Cauchy sequences $\left\{Z_{n}\right\}$ and $\left\{Z_{n}^{\prime}\right\}$ are also Cauchy.

Since $T(X)$ is complete, so there exists $a, b$ in $X$ such that:

$$
\left\{Z_{2 n+1}\right\} \rightarrow a \text { and }\left\{Z_{2 n+1}^{\prime}\right\} \rightarrow b
$$

Again convergence of the subsequences $\left\{Z_{2 n+1}\right\}$ and $\left\{Z_{2 n+1}\right\}$ implies the convergence of original Cauchy sequences $\left\{Z_{n}\right\}$ and $\left\{Z_{n}\right\}$ respectively such that

$$
\left\{Z_{n}\right\} \rightarrow a \text { and }\left\{Z_{n}\right\} \rightarrow b .
$$

It follows that the sequences $\left\{Z_{n}\right\},\left\{Z_{2 n+1}\right\},\left\{Z_{2 n+2}\right\}$ converge to $a$ and $\left\{Z_{n}\right\},\left\{Z_{2 n+1}^{\prime}\right\},\left\{Z_{2 n+2}^{\prime}\right\}$ converge to $b$.

Now $a, b \in T(X)$ implies the existence of $p, q \in X$ such that $T(p)=a, T(q)=b$, so that we have

$$
\begin{gathered}
\lim _{n \rightarrow \infty} Z_{2 n+1}=\lim _{n \rightarrow \infty} A\left(x_{2 n}, y_{2 n}\right)=\lim _{n \rightarrow \infty} T\left(x_{2 n+1}\right)=a=T(p) \\
\lim _{n \rightarrow \infty} Z_{2 n+2}=\lim _{n \rightarrow \infty} B\left(x_{2 n+1}, y_{2 n+1}\right)=\lim _{n \rightarrow \infty} S\left(x_{2 n+2}\right)=a=T(p)
\end{gathered}
$$

and

$$
\begin{aligned}
& \lim _{n \rightarrow \infty} Z_{2 n+1}^{\prime}=\lim _{n \rightarrow \infty} A\left(y_{2 n}, x_{2 n}\right)=\lim _{n \rightarrow \infty} T\left(y_{2 n+1}\right)=b=T(q) \\
& \lim _{n \rightarrow \infty} Z_{2 n+2}^{\prime}=\lim _{n \rightarrow \infty} B\left(y_{2 n+1}, x_{2 n+1}\right)=\lim _{n \rightarrow \infty} S\left(y_{2 n+2}\right)=b=T(q),
\end{aligned}
$$

From (3.19) and $\varphi(t)<t$,we obtain

$$
\begin{aligned}
F_{T\left(x_{2 n+1}\right), B(p, q)}(t) & \geq F_{T\left(x_{2 n+1}\right), B(p, q)}(\varphi(t))=F_{A\left(x_{2 n}, y_{2 n}\right), B(p, q)}(\varphi(t)) \\
& \geq\left[F_{S\left(x_{2 n}\right), T(p)}(t) F_{S\left(y_{2 n}\right), T(q)}(t)\right]^{1 / 2}
\end{aligned}
$$

Letting $n \rightarrow \infty$ in (3.30), we have $\lim _{n \rightarrow \infty} T\left(x_{2 n+1}\right)=B(p, q)$. Hence, $T(p)=B(p, q)=a$.

Similarly, we can show that $T(q)=B(q, p)=b$.

Since the pair $(B, T)$ are weakly compatible, so that $T(p)=B(p, q)=a$ implies $T(a)=$ $B(a, b)$, similarly, $T(b)=B(b, a)$.

Again, since $S(X)$ is complete, so that $a, b \in S(X)$, which implies the existence of $r, s$ in $X$, so that: $S(r)=a, S(s)=b$.

Similarly,we can show that $S(s)=A(s, r)=b$ and $S(r)=A(r, s)=a$. Since the pair $(A, S)$ are weakly compatible, it follows that: $A(a, b)=S(a)$ and $A(b, a)=S(b)$.

Step 3: We claim that $T a=b, T b=a$ and $S a=b, S b=a$ 
In fact, from (3.19) we have

$$
\begin{aligned}
F_{T\left(y_{2 n+1}\right), T a}(\varphi(t)) & =F_{A\left(y_{2 n}, x_{2 n}\right), B(a, b)}(\varphi(t)) \\
& \geq\left[F_{S\left(y_{2 n}\right), T(a)}(t) F_{S\left(x_{2 n}\right), T(b)}(t)\right]^{1 / 2} .
\end{aligned}
$$

Similarly, we have

$$
F_{T\left(x_{2 n+1}\right), T b}(\varphi(t)) \geq\left[F_{S\left(x_{2 n}\right), T(b)}(t) F_{S\left(y_{2 n}\right), T a}(t)\right]^{1 / 2}
$$

Suppose that $Q_{n}(t)=F_{S\left(y_{2 n}\right), T(a)}(t) F_{S\left(x_{2 n}\right), T(b)}(t)$.

By (3.31) and (3.32), we have

$$
\begin{gathered}
Q_{n}\left(\varphi^{n}(t)\right) \geq Q_{n-1}\left(\varphi^{n-1}(t)\right) \geq \ldots \geq Q_{0}(t) . \\
F_{T\left(y_{2 n+1}\right), T a}\left(\varphi^{n}(t)\right) \geq\left[Q_{0}(t)\right]^{1 / 2} ; \text { and } F_{T\left(x_{2 n+1}\right), T b}\left(\varphi^{n}(t)\right) \geq\left[Q_{0}(t)\right]^{1 / 2}
\end{gathered}
$$

Since $\left[Q_{0}(t)\right]^{1 / 2} \in D^{+}$. Since $\lim _{n \rightarrow \infty} \varphi^{n}(t)=0$, by Lemma 2.4 we conclude that

$$
\lim _{n \rightarrow \infty} T\left(y_{2 n+1}\right)=T a \text { and } \lim _{n \rightarrow \infty} T\left(x_{2 n+1}\right)=T b .
$$

This shows that $T a=b$ and $T b=a$. Hence, $B(a, b)=b$ and $B(b, a)=a$.

Similarly, we can show that $S a=b$ and $S b=a$. Hence, $A(a, b)=b$ and $A(b, a)=a$.

Step 4: Finally, we prove that $a=b$. By (3.19) we have

$$
\begin{aligned}
F_{a, b}(\varphi(t)) & =F_{A(b, a), B(a, b)}(\varphi(t)) \\
& \geq\left[F_{S(b), T(a)}(t) F_{S(a), T(b)}(t)\right]^{1 / 2}=F_{a, b}(t) .
\end{aligned}
$$

From (3.33), we have $F_{a, b}\left(\varphi^{n}(t)\right) \geq F_{a, b}(t)$. Using Lemma 2.4, we have $F_{a, b}(t)=1$,i.e., $a=$ $b$.The uniqueness of $a$ follows from (3.19). So, the proof of Theorem 3.4 is finished.

Theorem 3.5. Let $(X, F, \Delta)$ be a Menger metric space with $\Delta$ is a t-norm of H-type. Let $\varphi: \mathbb{R}^{+} \rightarrow \mathbb{R}^{+}$ be a gauge function such that $\varphi^{-1}(\{0\})=\{0\}, \varphi(t)<t$ and $\lim _{n \rightarrow \infty} \varphi^{n}(t)=+\infty$ for any $t>0$. Let $A: X \times X \rightarrow X, B: X \times X \rightarrow X, T: X \rightarrow X, S: X \rightarrow X$ be four mappings satisfying the following condition

(1) $A(X \times X) \subseteq T(X), B(X \times X) \subseteq S(X)$

(2)

$$
F_{A(x, y), B(u, v)}(t) \geq \min \left\{F_{S x, T u}(\varphi(t)), F_{S y, T v}(\varphi(t))\right\}
$$

for all $x, y, u, v \in X$ and $t>0$

(3)The pairs $(A, S)$ and $(B, T)$ are w-compatible.

(4) One of the subspaces $A(X \times X)$ or $T(X)$ and one of $B(X \times X)$ or $S(X)$ are complete.

Then there exists a unique point $a \in X$ such that $A(a, a)=S(a)=T(a)=B(a, a)=a$.

Proof. Step1: We show that $\left\{Z_{n}\right\}$ and $\left\{Z_{n}\right\}$ are Cauchy sequences.

By condition (1), we can construct two sequences $\left\{Z_{n}\right\}$ and $\left\{Z_{n}\right\}$ in $X$ such that 


$$
\begin{aligned}
& \left\{\begin{array}{l}
Z_{2 n+1}=A\left(x_{2 n}, y_{2 n}\right)=T\left(x_{2 n+1}\right) \\
Z_{2 n+2}=B\left(x_{2 n+1}, y_{2 n+1}\right)=S\left(x_{2 n+2}\right)
\end{array}\right. \\
& \left\{\begin{array}{l}
Z_{2 n+1}=A\left(y_{2 n}, x_{2 n}\right)=T\left(y_{2 n+1}\right) \\
Z_{2 n+2}^{\prime}=B\left(y_{2 n+1}, x_{2 n+1}\right)=S\left(y_{2 n+2}\right)
\end{array}\right.
\end{aligned}
$$

Suppose that $t>0$.From (3.34), we have

$$
\begin{array}{rlc}
F_{Z_{n}, Z_{n+1}}(t) & = & F_{T x_{n}, S x_{n+1}}(t) \\
& = & F_{A\left(x_{n-1}, y_{n-1}\right), B\left(x_{n}, y_{n}\right)}(t) \\
& \geq & \min \left\{F_{S x_{n-1}, T x_{n}}(\varphi(t)), F_{S y_{n-1}, T y_{n}}(\varphi(t))\right\} \\
& = & \min \left\{F_{Z_{n-1}, Z_{n}}(\varphi(t)), F_{Z_{n-1}^{\prime}, Z_{n}^{\prime}}(\varphi(t))\right\} \\
F_{Z_{n}^{\prime}, Z_{n+1}^{\prime}}(t) & = & F_{T y_{n}, S y_{n+1}}(t) \\
& = & F_{A\left(y_{n-1}, x_{n-1}\right), B\left(y_{n}, x_{n}\right)}(t) \\
\geq & \min \left\{F_{S y_{n-1}, T y_{n}}(\varphi(t)), F_{S x_{n-1}, T x_{n}}(\varphi(t))\right\} \\
& = & \min \left\{F_{Z_{n-1}^{\prime}, Z_{n}^{\prime}}(\varphi(t)), F_{Z_{n-1}, Z_{n}}(\varphi(t))\right\}
\end{array}
$$

Suppose that $E_{n}(t)=\min \left\{F_{Z_{n-1}^{\prime}}, Z_{n}^{\prime}(\varphi(t)), F_{Z_{n-1}, Z_{n}}(\varphi(t))\right\}$.Then, (3.35) and (3.36) we obtain $E_{n+1}(t) \geq E_{n}(\varphi(t))$.This implies that

$$
E_{n+1}(t) \geq E_{n}(\varphi(t)) \geq E_{n-1}\left(\varphi^{2}(t)\right) \geq \ldots \geq E_{1}\left(\varphi^{n}(t)\right) \text { and }
$$

Since $\lim _{t \rightarrow+\infty} E_{1}(t)=\lim _{t \rightarrow+\infty} \min \left\{F_{Z_{0}^{\prime}, Z_{1}^{\prime}}(\varphi(t)), F_{Z_{0}, Z_{1}}(\varphi(t))\right\}=1$ and $\lim _{n \rightarrow \infty} \varphi^{n}(t)=$ $+\infty$ for each $t>0$,we have

$\lim _{t \rightarrow+\infty} E_{1}\left(\varphi^{n}(t)\right)=1$.Moreover,by (3.35)-(3.37), we have $F_{Z_{n}, Z_{n+1}}(t) \geq E_{1}\left(\varphi^{n}(t)\right)$ and $F_{Z_{n}^{\prime}, Z_{n+1}^{\prime}}(t)$ $E_{1}\left(\varphi^{n}(t)\right)$.Hence, $\lim _{t \rightarrow+\infty} F_{Z_{n}, Z_{n+1}}(t)=1$ and $\lim _{t \rightarrow+\infty} F_{Z_{n}^{\prime}, Z_{n+1}^{\prime}}(t)=1$. This implies that

$$
\lim _{t \rightarrow+\infty} E_{n}(t)=1 \text { for all } t>0 .
$$

In the next we show that,for any $k \in \mathbb{Z}^{+}$,

$$
F_{Z_{n}, Z_{n+k}}(\varphi(t)) \geq \Delta^{k}\left(E_{n}(\varphi(t)-t)\right) \text { and } F_{Z_{n}^{\prime}, Z_{n+k}^{\prime}}(\varphi(t)) \geq \Delta^{k}\left(E_{n}(\varphi(t)-t)\right)
$$

In fact,this is obvious for $k=1$ by (3.35) and (3.36).Assume that (3.39) holds for some $k$.Since $\varphi(t)>t$,by (3.35), we have

$F_{Z_{n}, Z_{n+1}}(t) \geq E_{n}(\varphi(t)) \geq E_{n}(t)$.By (3.34) and (3.39),we have

$$
F_{Z_{n+1}, Z_{n+k+1}}(t) \geq \min \left\{F_{Z_{n}, Z_{n+k}}(\varphi(t)), F_{Z_{n}^{\prime}, Z_{n+k}^{\prime}}(\varphi(t))\right\} \geq \Delta^{k}\left(E_{n}(\varphi(t)-t)\right)
$$

Hence,by the monotonicity of $\Delta$,we have

$$
F_{Z_{n}, Z_{n+k+1}}(\varphi(t))=F_{Z_{n}, Z_{n+k+1}}(\varphi(t)-t+t)
$$




$$
\begin{aligned}
& \geq \Delta\left(F_{Z_{n}, Z_{n+1}}(\varphi(t)-t), F_{Z_{n+1}, Z_{n+k+1}}(t)\right) \\
& \geq \Delta\left(E_{n}(\varphi(t)-t), \Delta^{k}\left(E_{n}(\varphi(t)-t)\right)\right)=\Delta^{k+1}\left(E_{n}(\varphi(t)-t)\right)
\end{aligned}
$$

Similarly,we have $F_{Z_{n}^{\prime}, Z_{n+k+1}^{\prime}}(\varphi(t)) \geq \Delta^{k+1}\left(E_{n}(\varphi(t)-t)\right)$. Therefor,by induction,(3.39) holds for all $k \in \mathbb{Z}^{+}$.Furthermore, by (3.34) and (3.39) we have

$$
F_{Z_{n}, Z_{n+k}}(\varphi(t)) \geq \Delta^{k}\left(E_{n-1}(\varphi(t)-t)\right) \text { and } F_{Z_{n}^{\prime}, Z_{n+k}^{\prime}}(\varphi(t)) \geq \Delta^{k}\left(E_{n-1}(\varphi(t)-t)\right)
$$

Suppose that $\varepsilon>0$ and $\lambda \in(0,1]$ are given.Since $\Delta$ is a t-norm of H-type;there exists $\delta>0$ such that

$$
\Delta^{k}(s)>1-\lambda, \text { for all } s \in(1-\delta, 1] \text { and } k \in \mathbb{Z}^{+} \text {. }
$$

By (3.38),there exists $N \in \mathbb{Z}^{+}$such that $E_{n-1}(\varphi(\varepsilon)-\varepsilon)>1-\delta$ for all $n \geq N$.

Hence, from (3.40) and (3.41) we get

$F_{Z_{n}, Z_{n+k}}(\varepsilon)>1-\lambda$ and $F_{Z_{n}^{\prime}, Z_{n+k}^{\prime}}(\varepsilon)>1-\lambda$, for all $n \geq N$ and $k \in \mathbb{Z}^{+}$. This shows that, $\left\{Z_{n}\right\}$ and $\left\{Z_{n}^{\prime}\right\}$ are all Cauchy sequences.

Step 2: We show that $T(a)=B(a, b), T(b)=B(b, a)$ and $S(a)=A(a, b), S(b)=A(b, a)$ wirhout loss of generality,assume that $T(X)$ and $S(X)$ are complete. Now $\left\{Z_{2 n+1}\right\},\left\{Z_{2 n+2}\right\}$ and $\left\{Z_{2 n+1}^{\prime}\right\},\left\{Z_{2 n+2}^{\prime}\right\}$ being respective subsequences of Cauchy sequences $\left\{Z_{n}\right\}$ and $\left\{Z_{n}^{\prime}\right\}$ are also Cauchy.

Since $T(X)$ is complete, so there exists $a, b$ in $X$ such that:

$$
\left\{Z_{2 n+1}\right\} \rightarrow a \text { and }\left\{Z_{2 n+1}^{\prime}\right\} \rightarrow b
$$

Again convergence of the subsequences $\left\{Z_{2 n+1}\right\}$ and $\left\{Z_{2 n+1}^{\prime}\right\}$ implies the convergence of original Cauchy sequences $\left\{Z_{n}\right\}$ and $\left\{Z_{n}\right\}$ respectively such that

$$
\left\{Z_{n}\right\} \rightarrow a \text { and }\left\{Z_{n}^{\prime}\right\} \rightarrow b
$$

It follows that the sequences $\left\{Z_{n}\right\},\left\{Z_{2 n+1}\right\},\left\{Z_{2 n+2}\right\}$ converge to $a$ and $\left\{Z_{n}^{\prime}\right\},\left\{Z_{2 n+1}^{\prime}\right\},\left\{Z_{2 n+2}^{\prime}\right\}$ converge to $b$.

Now $a, b \in T(X)$ implies the existence of $p, q \in X$ such that $T(p)=a, T(q)=b$, so that we have

$$
\begin{gathered}
\lim _{n \rightarrow \infty} Z_{2 n+1}=\lim _{n \rightarrow \infty} A\left(x_{2 n}, y_{2 n}\right)=\lim _{n \rightarrow \infty} T\left(x_{2 n+1}\right)=a=T(p) \\
\lim _{n \rightarrow \infty} Z_{2 n+2}=\lim _{n \rightarrow \infty} B\left(x_{2 n+1}, y_{2 n+1}\right)=\lim _{n \rightarrow \infty} S\left(x_{2 n+2}\right)=a=T(p)
\end{gathered}
$$

and

$$
\begin{aligned}
& \lim _{n \rightarrow \infty} Z_{2 n+1}^{\prime}=\lim _{n \rightarrow \infty} A\left(y_{2 n}, x_{2 n}\right)=\lim _{n \rightarrow \infty} T\left(y_{2 n+1}\right)=b=T(q) \\
& \lim _{n \rightarrow \infty} Z_{2 n+2}^{\prime}=\lim _{n \rightarrow \infty} B\left(y_{2 n+1}, x_{2 n+1}\right)=\lim _{n \rightarrow \infty} S\left(y_{2 n+2}\right)=b=T(q),
\end{aligned}
$$

From (3.34), we obtain

$$
F_{T\left(x_{2 n+1}\right), B(p, q)}(t)=F_{A\left(x_{2 n}, y_{2 n}\right), B(p, q)}(t) \geq \min \left\{F_{S\left(x_{2 n}\right), T(p)}(\varphi(t)), F_{S\left(y_{2 n}\right), T(q)}(\varphi(t))\right\}
$$


Letting $n \rightarrow \infty$ in (3.42), we have $\lim _{n \rightarrow \infty} T\left(x_{2 n+1}\right)=B(p, q)$. Hence, $T(p)=B(p, q)=a$.In the same manner we can show that $T(q)=B(q, p)=b$.

Since the pair $(B, T)$ are weakly compatible, so that $T(p)=B(p, q)=a$ implies $T(a)=$ $B(a, b)$, similarly, $T(b)=B(b, a)$.

Again, since $S(X)$ is complete, so that $a, b \in S(X)$, which implies the existence of $r, s$ in $X$, so that: $S(r)=a, S(s)=b$.

Similarly,we can show that $S(s)=A(s, r)=b$ and $S(r)=A(r, s)=a$.

Since the pair $(A, S)$ are weakly compatible, it follows that: $A(a, b)=S(a)$ and $A(b, a)=$ $S(b)$.

Step 3: We claim that $T a=b, T b=a$ and $S a=b, S b=a$

In fact, from (3.34) we have

$$
\begin{aligned}
F_{T\left(y_{2 n}\right), T a}(t) & =F_{A\left(y_{2 n}, x_{2 n}\right), B(a, b)}(t) \\
& \geq \min \left\{F_{S\left(y_{2 n-1}\right), T(a)}(\varphi(t)), F_{S\left(x_{2 n-1}\right), T(b)}(\varphi(t))\right\}
\end{aligned}
$$

Similarly,we have

$$
F_{T\left(x_{2 n}\right), T b}(t) \geq \min \left\{F_{S\left(x_{2 n-1}\right), T(b)}(t), F_{S\left(y_{2 n-1}\right), T a}(t)\right\}
$$

Suppose that $M_{n}(t)=\min \left\{F_{T\left(x_{2 n}\right), T b}(t), F_{T\left(y_{2 n}\right), T a}(t)\right\}$. From (3.43) and (3.44) it follows that

$$
M_{n}(t) \geq M_{n-1}(\varphi(t)) \geq \ldots \geq M_{0}\left(\varphi^{n}(t)\right) .
$$

Since $\lim _{n \rightarrow \infty} \varphi^{n}(t)=+\infty$, we have

$$
M_{0}\left(\varphi^{n}(t)\right)=\min \left\{F_{T\left(x_{0}\right), T b}(t), F_{T\left(y_{0}\right), T a}(t)\right\} \rightarrow 1 \text { as } n \rightarrow \infty
$$

This shows that $M_{n}(t) \rightarrow 1$ as $n \rightarrow \infty$,and so

$$
\lim _{n \rightarrow \infty} T\left(y_{2 n+1}\right)=T a \text { and } \lim _{n \rightarrow \infty} T\left(x_{2 n+1}\right)=T b .
$$

Hence, $T a=b$ and $T b=a$.

Similarly,we can show that $S a=b$ and $S b=a$. Hence, $A(a, b)=b$ and $A(b, a)=a$.

Step 4: Finally, we prove that $a=b$.

By (3.34) we have

$$
F_{a, b}(t)=F_{A(b, a), B(a, b)}(t) \geq \min \left\{F_{S(b), T(a)}(\varphi(t)), F_{S(a), T(b)}(\varphi(t))\right\}=F_{a, b}(\varphi(t)) .
$$

From (3.45), we have $F_{a, b}(t) \geq F_{a, b}\left(\varphi^{n}(t)\right)$.

Letting $n \rightarrow \infty$, we have $F_{a, b}(t)=1$, i.e., $a=b$. Since the uniqueness of $a$ follows from (3.34), the proof of Theorem 3.5 is completed.

We give an example to illustrate the validity of Theorem 5 .

Example 3.1. Let $X=[0,1)$ and

$$
F_{x, y}(t)=\frac{t}{t+|x-y|}
$$


Let $A: X \times X \rightarrow X, B: X \times X \rightarrow X, T: X \rightarrow X$ and $S: X \rightarrow X$ mappings, such that:

$$
\begin{aligned}
& A(x, y)=\left\{\begin{array}{ccc}
\frac{x^{2}-y^{2}}{6} & \text { if } & x \geq y \\
0 & \text { if } & x<y
\end{array}\right. \\
& B(x, y)=\left\{\begin{array}{ccc}
\frac{x-y}{6} & \text { if } & x \geq y \\
0 & \text { if } & x<y
\end{array}\right.
\end{aligned}
$$

and

$$
S(x)=\frac{x^{2}}{2}, T(x)=\frac{x}{2}
$$

Clearly, $A(X \times X) \subseteq T(X)$ and $B(X \times X) \subseteq S(X)$ and $S(X)$ and $T(X)$ are complete subspace of $X$.

Next we show that our results can be used for this case.

Let us prove that the pairs $(A, S)$ and $(B, T)$ are w-compatible. It is obtained that:

$$
A(x, y)=S(x) \text { and }: A(y, x)=S(y) \text { if and only if } x=y=0 .
$$

Since $A(S(0), S(0))=S(A(0,0))$, the mappings $A$ and $S$ are wekly compatible. And

$$
B(x, y)=T(x) \text { and } B(y, x)=T(y) \text { if and only if } x=y=0 .
$$

Since $B(T(0), T(0))=T(B(0,0))$.

Finally, we prove that for $x, y, u, v \in X$,

$$
F_{A(x, y), B(u, v)}(\varphi(t)) \geq \Delta\left(F_{S x, T u}(t), F_{S y, T v}(t)\right) .
$$

Let $\varphi:(0, \infty) \rightarrow(0, \infty)$ by $\varphi(t)=\frac{3}{2} t$, Then $\lim _{n \rightarrow+\infty} \varphi^{n}(t)=+\infty$ for any $t>0$. we distinguish the following cases:

Cas 1: $x \geq y$ and $u \geq v$

$$
\begin{aligned}
F_{A(x, y), B(u, v)}(t) & =\frac{t}{t+\left|\frac{x^{2}-y^{2}}{6}-\frac{u-v}{6}\right|} \\
& =\frac{3 t}{3 t+\left|\left(\frac{x^{2}}{2}-\frac{u}{2}\right)-\left(\frac{y^{2}}{2}-\frac{v}{2}\right)\right|} \\
& \geq \operatorname{Min}\left\{\frac{\frac{3}{2} t}{\frac{3}{2} t+\left|x^{2}-u\right|}, \frac{\frac{3}{2} t}{\frac{3}{2} t+\left|y^{2}-v\right|}\right\} \\
& =\operatorname{Min}\left\{F_{S x, T u}(\varphi(t)), F_{S y, T v}(\varphi(t))\right\} .
\end{aligned}
$$

Cas 2: $x \geq y$, and $u \leq v$

$$
\begin{aligned}
F_{A(x, y), B(u, v)}(t) & =\frac{t}{t+\left|\frac{x^{2}-y^{2}}{6}-0\right|} \\
& =\frac{3 t}{3 t+\left|\frac{x^{2}-y^{2}}{2}\right|}
\end{aligned}
$$




$$
\begin{aligned}
& =\frac{3 t}{3 t+\left|\left(\frac{x^{2}}{2}-\frac{u}{2}\right)-\left(\frac{y^{2}}{2}-\frac{u}{2}\right)\right|} \\
& \geq \frac{\frac{3}{2} t}{\frac{3}{2} t+\left|\frac{x^{2}}{2}-\frac{u}{2}\right|} \\
& \geq \operatorname{Min}\left\{F_{S x, T u}(\varphi(t)), F_{S y, T v}(\varphi(t))\right\}
\end{aligned}
$$

Cas 3: $x \leq y$, and $u \geq v$

$$
\begin{aligned}
F_{A(x, y), B(u, v)}(t) & =\frac{t}{t+\left|0-\frac{u-v}{6}\right|} \\
& =\frac{3 t}{3 t+\left|\left(\frac{x^{2}}{2}-\frac{u}{2}\right)-\left(\frac{v}{2}-\frac{x^{2}}{2}\right)\right|} \\
& \geq \frac{\frac{3}{2} t}{\frac{3}{2} t+\left|\frac{x^{2}}{2}-\frac{u}{2}\right|} \\
& \geq \operatorname{Min}\left\{F_{S x, T u}(\varphi(t)), F_{S y, T v}(\varphi(t))\right\}
\end{aligned}
$$

Cas 4: $x \leq y$, and $u \leq v$

$$
\begin{aligned}
F_{A(x, y), B(u, v)}(t) & =\frac{t}{t+0} \\
& =1 \\
& \geq \operatorname{Min}\left\{F_{S x, T u}(\varphi(t)), F_{S y, T v}(\varphi(t))\right\}
\end{aligned}
$$

Hence, all the hypotheses of Theorem 3.5 hold. Clearly $(0,0)$ is the unique common coupled fixed point of $A, B, S$ and $T$.

\section{Application to integral equations}

As an application of the coupled fixed point theorems established in section 3 of our paper, we study the existence and uniqueness of the solution to a Fredholm nonlinear integral equation.

We shall consider the following integral equation,

$$
x(p)=\int_{a}^{b}\left(K_{1}(p, q)+K_{2}(p, q)\right)[f(q, x(q))+g(q, x(q))] d q+h(p),
$$

for all $p \in I=[a, b]$.

Let $\Theta$ denote the set of all functions $\theta:[0,1] \rightarrow[0,1]$ satisfying

$\left(i_{\theta}\right) \theta$ is non-decreasing,

$\left(i i_{\theta}\right) \theta(p) \leq p$.

We assume that the functions $K_{1}, K_{2}, f, g$ fulfill the following conditions: Assumption 4.1. 
(i) $K_{1}(p, q) \geq 0$ and $K_{2}(p, q) \leq 0$ for all $p, q \in I$,

(ii) There exists $\theta \in \Theta$ such that for all $x, y \in \mathbb{R}$ with $x \geq y$, the following conditions hold:

$$
0 \leq f(q, x)-f(q, y) \leq \lambda \theta(x-y)
$$

and

$$
-\mu \theta(x-y) \leq g(q, x)-g(q, y) \leq 0,
$$

$$
\max \{\lambda, \mu\} \sup _{p \in I} \int_{a}^{b}\left[K_{1}(p, q)-K_{2}(p, q)\right] d q \leq \frac{1}{4}
$$

Consider the integral equation (4.1) with $K_{1}, K_{2} \in C(I \times I, \mathbb{R})$ and $h \in C(I, \mathbb{R})$. Suppose that Assumption 4.1 is satisfied. Then the integral equation (4.1) has a unique solution in $C(I, \mathbb{R})$.

Proof. Consider $X=C(I, \mathbb{R})$. It is easy to check that $(X, F, L, *, \diamond)$ is a complete Menger metric space with respect to the distribution distance

$$
F_{x, y}(t)=\frac{t}{t+|x-y|} \text {, for all } x, y \in X \text { and } t>0 \text { with } x * y=\min (x, y) \text { for all } x, y \in X \text {. }
$$

Define now the mapping $T: X \times X \rightarrow X$ by

$$
\begin{aligned}
T(x, y)(p)= & \int_{a}^{b} K_{1}(p, q)[f(q, x(q))+g(q, y(q))] d q \\
& +\int_{a}^{b} K_{2}(p, q)[f(q, y(q))+g(q, x(q))] d q+h(p)
\end{aligned}
$$

for all $p \in I$ and $k=\frac{1}{2}$ for all $t>0$. Now,for all $x, y, u, v \in X$, using (4.2) and (4.3), we have

$$
\begin{aligned}
& T(x, y)(p)-T(u, v)(p) \\
= & \int_{a}^{b} K_{1}(p, q)[f(q, x(q))+g(q, y(q))] d q \\
& +\int_{a}^{b} K_{2}(p, q)[f(q, y(q))+g(q, x(q))] d q \\
& -\int_{a}^{b} K_{1}(p, q)[f(q, u(q))+g(q, v(q))] d q \\
& -\int_{a}^{b} K_{2}(p, q)[f(q, v(q))+g(q, u(q))] d q \\
= & \int_{a}^{b} K_{1}(p, q)[f(q, x(q))-f(q, u(q))+g(q, y(q))-g(q, v(q))] d q \\
& +\int_{a}^{b} K_{2}(p, q)[f(q, y(q))-f(q, v(q))+g(q, x(q))-g(q, u(q))] d q \\
= & \int_{a}^{b} K_{1}(p, q)[(f(q, x(q))-f(q, u(q)))-(g(q, v(q))-g(q, y(q)))] d q
\end{aligned}
$$




$$
\begin{aligned}
& -\int_{a}^{b} K_{2}(p, q)[(f(q, v(q))-f(q, y(q)))-(g(q, x(q))-g(q, u(q)))] d q \\
\leq & \int_{a}^{b} K_{1}(p, q)[\lambda \theta(x(q)-u(q))+\mu \theta(v(q)-y(q))] d q \\
& -\int_{a}^{b} K_{2}(p, q)[\lambda \theta(v(q)-y(q))+\mu \theta(x(q)-u(q))] d q
\end{aligned}
$$

Since the function $\theta$ is non-decreasing and so we have

$$
\theta(x(q)-u(q)) \leq \theta(|x(q)-u(q)|)
$$

and

$$
\theta(v(q)-y(q)) \leq \theta(|v(q)-y(q)|)
$$

hence by (4.6), in view of the fact $K_{2}(p, q) \leq 0$, we get

$$
\begin{aligned}
& |T(x, y)(p)-T(u, v)(p)| \\
\leq & \int_{a}^{b} K_{1}(p, q)[\lambda \theta(|x(q)-u(q)|)+\mu \theta(|v(q)-y(q)|)] d q \\
& -\int_{a}^{b} K_{2}(p, q)[\lambda \theta(|v(q)-y(q)|)+\mu \theta(|x(q)-u(q)|)] d q \\
\leq & \int_{a}^{b} K_{1}(p, q)[\max \{\lambda, \mu\} \theta(|x(q)-u(q)|)+\max \{\lambda, \mu\} \theta(|v(q)-y(q)|)] d q \\
& -\int_{a}^{b} K_{2}(p, q)[\max \{\lambda, \mu\} \theta(|v(q)-y(q)|)+\max \{\lambda, \mu\} \theta(|x(q)-u(q)|)] d q
\end{aligned}
$$

as all the quantities on the right hand side of (4.6) are non-negative. Now by using (4.5), we get

$$
\begin{aligned}
& |T(x, y)-T(u, v)| \\
\leq & \max \{\lambda, \mu\} \int_{a}^{b}\left[K_{1}(p, q)-K_{2}(p, q)\right] d q \cdot[\theta(|x(q)-u(q)|)+\theta(|v(q)-y(q)|)] \\
\leq & \max \{\lambda, \mu\} \sup _{p \in I} \int_{a}^{b}\left[K_{1}(p, q)-K_{2}(p, q)\right] d q \cdot[\theta(|x(q)-u(q)|)+\theta(|v(q)-y(q)|)] \\
\leq & \frac{\theta(|x-u|)+\theta(|v-y|)}{4}
\end{aligned}
$$

Thus

$$
2|T(x, y)-T(u, v)| \leq \frac{\theta(|x-u|)+\theta(|v-y|)}{2}
$$

Now, since $\theta$ is nondecreasing, we have

$$
\begin{aligned}
& \theta(|x-u|) \leq \theta(|x-u|)+\theta(|y-v|) \\
& \theta(|y-v|) \leq \theta(|x-u|)+\theta(|y-v|)
\end{aligned}
$$


which, by using $\left(i i_{\theta}\right)$, this implies

$$
\begin{aligned}
\frac{\theta(|x-u|)+\theta(|y-v|)}{2} & \leq \theta(|x-u|+|y-v|) \\
& \leq|x-u|+|y-v| \\
& \leq 2 \max \{|x-u|,|y-v|\},
\end{aligned}
$$

and so

$$
\frac{\theta(|x-u|)+\theta(|y-v|)}{2} \leq \max \{|x-u|,|y-v|\}
$$

Thus, by (4.9) and (4.12), we get

$$
2|T(x, y)-T(u, v)| \leq \max \{|x-u|,|y-v|\}
$$

Now, it follows that

$$
\begin{aligned}
F_{T(x, y), T(u, v)}(k t) & =F_{T(x, y), T(u, v)}\left(\frac{t}{2}\right) \\
& =\frac{\frac{t}{2}}{\frac{t}{2}+|T(x, y)-T(u, v)|} \\
& =\frac{t}{t+2|T(x, y)-T(u, v)|} \\
& \geq \frac{t}{t+\max \{|x-u|,|y-v|\}} \\
& \geq \min \left\{\frac{t}{t+|x-u|}, \frac{t}{t+|y-v|}\right\} \\
& \geq \min \left\{F_{x, u}(t), F_{y, v}(t)\right\}
\end{aligned}
$$

Thus

$$
F_{T(x, y), T(u, v)}(k t) \geq F_{x, u}(t) * F_{y, v}(t)
$$

show that all hypotheses of Corollary 3.2 are satisfied.

This proves that $T$ has a unique fixed point $a \in X$, that is, $a=T(a, a)$ and therefore $a \in$ $C(I, \mathbb{R})$ is the unique solution of the integral equation (4.1).

\section{References}

[1] M. Abbas, M. Ali Khan, S. Radenovic. Common coupled fixed point theorems in cone metric spaces for $w$-compatlble mappings, Applied Mathematics and Computation 217 (2010) 195-202.

[2] T.G. Bhaskar and V. Lakshmikantham, Fixed point theorems in partially ordered metric spaces and applications,Nonlinear Anal. 65(7) (2006) 1379-1393

[3] L. Ciric, D. Mihet, R. Saadati, Monotone generalized contractions in partially ordered probabilistic metric spaces, Topology and its Applications 156(2009), 2838-2844. 1

[4] L. Ciric, R. Agarwal, B. Samet, Mixed monotone-generalized contractions in partially ordered probabilistic metric spaces, Fixed Point Theory and Applications 2011,2011:56 doi:10.1186/1687-1812-2011-56. 1

[5] J.-X. Fang, Common fixed point theorems of compatible and weakly compatible maps in Menger spaces, Nonlinear Analysis.Theory, Methods \& Applications 71 (2009),1833-1843. 
[6] O. Hadzic, E.Pap, Fixed Point Theory in Probabilistec Metric Spaces, Kluwer Academic Publishers, Dordrecht,2001.

[7] O. Hadzic, E. Pap, M. Budincevic, Countable extension of triangular norms and their applications to the fixed point theory in probabilistc metric spaces, Kybernetika 38 (3) (2002),363-381.

[8] M. Jain, S. Kumar, R. Chugh. Coupled fixed point theorems for weak compatible mappings in fuzzy metric spaces, Annals of fuzzy Mathematics and Informatics (2013) 321-336.

[9] I. Kramosil, J. Michalek, Fuzzy metrics and statistical metric spaces, Kybernetika 11 (1975),336-344.

[10] V. Lakshmikantham, L. Ciric, Coupled fixed point theorems for nonlinear contractions in partially ordered metric spaces, Nonlinear Analysis. Theory,Methods \& Applications 70 (2009), 4341-4349.

[11] Y. Liu, Z. Li, Coincidence point theorems in probabilistic and fuzzy metric spaces, Fuzzy Sets and Systems 158 (2007) 58-70.

[12] B. Schweizer, A. Sklar, Probabilistic Metric Spaces, North-Holland, Amsterdam, 1983.

[13] B. Schweizer, A. Sklar, Statistical metric spaces, Pacific J.Math. 10 (1960) 313-334.

[14] B. Schweizer, A. Sklar, E. Thorp, The metrization of statistical metric spaces, Pacific J.Math. 10 (1960) 673-675.

[15] B. Schweizer, A. Sklar, Statistical metric spaces, Paci...c J.Math. 10 (1960) 313-334.

[16] B. Schweizer, A. Sklar, E,Thorp, The metrization of statistical metric spaces, Paci. .. c J.Math. 10 (1960) 673-675

[17] S. Sedghi, I. Altun, N. Shobe, Coupled fixed point theorems for contractions in fuzzy metric spaces, Nonlinear Analysis.Theory,Methods \& Applications 72 (2010), 1298-1304. 1

[18] W. Sintunavarat, P. Kumam, Common fixed points for R-weakly commuting in fuzzy metric spaces, Ann.Univ.Ferrara 58,389-406 (2012)

[19] J. Xiao, Xing-Hua Zhu, Yin-Fang Cao. Common coupled fixed point results for probabilistic $\varphi$-contractions in Menger spaces.Nonlinear Analysis 74 (2011) 4589-4600.

[20] Xin-Qi Hu, Common Coupled Fixed Point Theorems for Contractive Mapping in Fuzzy Metric Spaces, Fixed Point Theory and Applications Volume 2011, Article ID 363716, doi:10.1155/2011/363716.

[21] Xin-Qi Hu, Xiao-Yan Ma, Coupled coincidence point theorems under contractive conditions in partially ordered probabilistc metric spaces, Nonlinear Analysis.Theory,Methods \& Applications 74(2011), 6451-6458.

[22] Xing-Hua Zhu, Jian-Zhong Xiao, Note on "Coupled fixed point theorems for contractions in fuzzy metric spaces", Nonlinear Analysis.Theory,Methods \& Applications 74 (2011), 5475-5479. 